DOI 10.5216/ia.v45i1.62689

\title{
NEOLIBERALISMO Y DEMOCRACIA, UN MATRIMONIO CONDENADO AL DIVORCIO CON UN HIJO BASTARDO LLAMADO EDUCACIÓN
}

\author{
ROBERTO DONOSO TORRES \\ Universidad de Los Andes, Mérida, Venezuela
}

\begin{abstract}
RESUMEN: Utilizando el mito como criterio de análisis se examina la teoría y práctica del neoliberalismo en sus relaciones con el desarrollo democrático y la educación. Se develan incongruencias y fantasías del neoliberalismo en su aplicación con especial referencia a su incidencia en la economía. En ese contexto la educación es considerada con criterios mercantiles, desdibujando su perfil humanístico y su condición de servicio público para hacer de ella un recurso más para la obtención de beneficios económicos. Estas relaciones entre neoliberalismo, democracia y educación permiten afirmar sus incompatibilidades para inferir que el neoliberalismo no es un escenario para el desarrollo democrático ni menos para la educación pública.
\end{abstract}

Palabras clave: Mito. Neoliberalismo. Democracia. Educación.

Si quita usted a un hombre vulgar la mentira, le quitará la felicidad a la vez Enrique Ibsen ${ }^{7}$

\section{PRESENTACIÓN}

Para examinar la espúrea relación marital entre neoliberalismo y democracia como unión que se auto repele, se ha elegido al mito como enfoque para abordarla debido a que no es un sendero muy concurrido a pesar de su vigencia y presencia omnipresente en todos los ámbitos de la vida. Al examinar los valiosos estudios sobre el mito descubrimos que nadie tiene el derecho a pensar que el examen del Neoliberalismo, la democracia y la educación como una familia conflictiva al amparo del mito, necesariamente es peyorativo, pues si el mito forma parte de la condición humana, el Neoliberalismo en tanto respuesta humana de los partidarios del modelo capitalista esencialmente a problemas de su desarrollo, no está exento de mitología que se intentará develar. Claro está que lo que complejiza las cosas es que el 
mito no sólo describe sino simultáneamente conlleva valores, imaginarios sociales, pautas de comportamiento. En su sentido negativo es sinónimo de cuento, fábula, relato fantasioso. En su sentido positivo resume las tradiciones cargadas de simbolismo que conservadas en la memoria de los pueblos y transmitidas de generación en generación generan una cultura. La intención es intentar examinar ambas vertientes del mito porque son válidas, pues, efectivamente el Neoliberalismo tiene mucho de cuento, de fábula, de ofertas engañosas, de mentiras presentadas como verdades y al mismo tiempo esta ideología política es heredera de una tradición cargada de historia, valores y tradiciones con insignes representantes.

Los estudios sobre el Neoliberalismo, especialmente en el campo de la economía, evidencian que su propósito es atender los desafíos acuciantes de la nueva fase del desarrollo capitalista, que incluso en las potencias desarrolladas del norte, a pesar de todos sus oropeles, no logra satisfacer las aspiraciones de sus respectivos conglomerados humanos, lo cual posibilita vislumbrar sus pliegues mitológicos. Si la mirada se centra en Latinoamérica, que tiene el mérito de contar con una nación que sirvió de laboratorio en vivo para aplicar los tratamientos y recetas recomendadas por el Neoliberalismo, la mitología se hace patente especialmente al considerar la convulsa situación que se desarrolla en la región como consecuencia del recetario neoliberal y que tiene un desenlace incierto, aunque no es erróneo pensar que el modelo utilizará todos los recursos a su alcance siendo el más visible la brutal represión de los cuerpos de seguridad con tal mantenerse y, a lo sumo, asumir algunas modificaciones que con una buena cosmetología le permitirá pasar a una nueva etapa de sobrevivencia.

Toda actividad humana tiene una historia, o, para no exagerar, una historieta. El texto que se expone no puede ser una excepción. Al recibir la invitación cordial para un Dossier especial sobre Neoliberalismo, educación y democracia, justo en el momento en que se daba término al primer borrador, estalló en Chile, la joya de la corona del Neoliberalismo, una bomba de tiempo cuyos efectos aún persisten. La chispa que encendió la hoguera, al igual que en el pasado reciente ${ }^{2}$, la proporcionaron los estudiantes de enseñanza secundaria que, frente al alza del transporte en metro, decidieron omitir el pago saltando los controles. La ciudadanía, lejos de atender las críticas que se desataron por los medios de comunicación contra un acto que se calificaba como "atentatorio al orden público", "una violación injustificada", "una expresión de anarquismo intolerable", y otros calificativos de ese jaez, se sumó con elevado entusiasmo a la rebeldía juvenil, y lo que se esperaba se resolviera con medidas punitivas tal como fue anunciado por la Ministra de Transporte, se convirtió en un feroz terremoto social de efectos insospechados y que puso al desnudo los mitos y/o sofismas del modelo neoliberal que por más de cinco décadas mantuvieron a ese país como un paradigma para la región. En efecto, tan convencida estaba la elite chilena de las bondades del modelo que administraban junto con la izquierda neoliberal, que el presidente de Chile, Sebastián Piñera se permitió declarar el pasado 8 de octubre en el programa Mucho Gusto del canal de televisión Mega de la capital chilena: "En medio de esta América Latina convulsionada veamos a Chile, nuestro país es un verdadero oasis ${ }^{3}$ con una democracia estable, el país está 
TORRES, R. D

creciendo, estamos creando 176 mil empleos al año, los salarios están mejorando"4, un verdadero compendio de entusiasmo exultante. Hay que agregar que en su larga actividad política ha mostrado ser un saltimbanqui. Un Dios Jano con dos caras opuestas. Apenas transcurridos quince días de aquella declaración y luego de masivas e iracundas movilizaciones, el mismo presidente, en tono dramático salía a declarar: "Estamos en guerra contra un enemigo poderoso, implacable, que no respeta a nada ni a nadie, que está dispuesto a usar la violencia y la delincuencia sin ningún límite" ${ }^{\text {. }}$. Un río subterráneo muy profundo corría bajo la superficie de un país que se mostraba para muchos, probablemente ingenuos o interesados, como un modelo a seguir. Chile en estos momentos está en la mira de los estudiosos de los procesos sociales, especialmente porque, como está dicho, era la carta de presentación del modelo neoliberal. Se desnudaba una realidad que había sido proclamada por sus supuestas virtudes, porque era la herencia dejada por la dictadura cívico militar de la década de los setenta y continuada sin mayores alteraciones, y por el contrario con mayor profundización, por la democracia recuperada. Puestas así las cosas el mito del neoliberalismo es necesario examinarlo. Debe quedar en claro que la intención no es recorrer los complicados y a veces crípticos análisis que sobre el capitalismo en general y el neoliberalismo en particular desarrollan los economistas, pues, quien escribe no lo es, ni tampoco el objetivo de esta exposición.

\section{MITO DEL CRESCIMIENTO}

El motor que mueve la economía de los países, que estimula el desarrollo, que enorgullece a los gobernantes, es el crecimiento ${ }^{6}$. Denodados esfuerzos se despliegan para alcanzar la mayor tasa de crecimiento interanual y cuando el "motor de la economía mundial", China, sufre una baja en su tasa de crecimiento, las economías del mundo hacen sonar sus alarmas pues se asoman tiempos difíciles. ¿Por qué?, simplemente porque se disminuye la producción, se reduce la demanda y el consumo, desciende la tasa de ganancia y consecuentemente se estanca la acumulación y es necesario aplicar ajustes, el primero de todos, expulsar mano de obra y la cesantía o paro forzoso crece, con lo cual las desigualdades en el acceso a los bienes básicos se incrementan, las brechas sociales se agudizan con lo que se crea un caldo de cultivo para eventuales conflictos sociales. Es decir, sin crecimiento el modelo pierde su supuesto equilibro. Claro está que el capitalismo en el caso de crisis entra en otra fase de acumulación ${ }^{7}$. No se trata de un reduccionismo ni un simplismo a ultranza, pues los procesos descritos no son mecánicos, lineales ni secuenciales, sino que conforman una compleja dinámica en la que intervienen distintos actores, entre otros, el más importante es el Estado nacional que frente a coyunturas que golpean duramente a la población desarrolla políticas sociales de carácter asistencial aunque las más de la veces son un recurso más bien publicitario antes que efectivo.

Para que haya crecimiento es necesario el consumo. El principal grupo humano al cual va dirigido el mensaje del derroche, de la búsqueda de la novedad, de la primicia tecnológica es la juventud. Para ello una formidable maquinaria publicitaria que cuenta con el aporte de diversos profesionales que estudian el comportamiento humano, desata el 
"espectáculo del deseo"8 para la mayor gloria del inversionista. La espiral creciente de demandas que desata un apetito voraz por adquirir bienes muebles, baratijas, bagatelas, choca con los límites del poder adquisitivo de la mayoría de la población ${ }^{9}$, situación que se agrava al considerar la habitual práctica de una producción para el desecho, una advertencia que ya tiene décadas de existencia ${ }^{10}$, pero si el trabajo es escaso, y la inflación es un fantasma siempre presente, entonces la frustración y el desencanto son parte del panorama cultural.

El crecimiento tiene, además de la vertiente económica, un componente demográfico importantísimo. La población mundial experimenta un constante crecimiento lo que significa mayores demandas en todos los renglones de la existencia humana. En la actualidad, si bien las cifras tienen matices diferenciales, podemos admitir que la población mundial es del orden de los 7.700 .000 .000 (siete mil setecientos millones). Sin embargo, "Se espera que la población mundial aumente en 2.000 millones de personas en los próximos 30 años, pasando de los 7.700 millones actuales a los 9.700 millones en 2050, pudiendo llegar a un pico de cerca de 11.000 millones para $2100^{\prime \prime 1}$. El crecimiento constante de la población plantea inquietudes. Para el pensamiento conservador y liberal, es necesario aplicar políticas de control de la natalidad, lo que se ha llevado a cabo pasando por encima de barreras éticas importantes en un tema de esta naturaleza. Quienes están en la vereda del frente de los conservadores, sostiene que el problema fundamental es el de la distribución de los bienes y servicios cuyo reparto es pornográficamente desigual. Independientemente de estas posiciones encontradas, la interrogante de fondo es, ¿cuál es el límite del crecimiento económico que no altere el equilibrio planetario? Una preocupación que en 1970 llevó al Club de Roma, una organización privada de empresarios, políticos e intelectuales, a encargar al M.I.T. un estudio sobre las tendencias del crecimiento económico y los problemas asociados.

Consecuentemente hoy, cuando la humanidad está enfrentada a los severos efectos del cambio climático, cuando se prevén conflictos por el agua, entre otras manifestaciones de un crecimiento económico ilimitado en la producción de bienes, muchos de los cuales responden a "necesidades" creadas por poderosos aparatos publicitarios, el Informe en referencia adquiere singular trascendencia especialmente si tenemos presente que "nada puede crecer indefinidamente en un medio finito"12. Es posible que a futuro alguna aplicación tecnológica, quizás una guerra de grandes proporciones, alguna pandemia, algún cambio drástico en los hábitos de consumo posibiliten el equilibrio entre crecimiento y sustentación del planeta. Mientras esto no ocurra, la humanidad transita por preocupantes senderos de riesgos. Sin embargo, son las potencias económicas ${ }^{13}$ las que tienen la primera responsabilidad en la contaminación, pero interesadas en la competencia por alcanzar el mayor índice de crecimiento, prestan escasa o nula atención a las consecuencias de un crecimiento ilimitado. Paradigmática es la posición de los Estados Unidos, uno de los países de mayor consumo de energía, que se ha negado a firmar el Protocolo de Kioto. De manera que el crecimiento, aspiración del capitalismo neoliberal tiene un límite, un techo que es su propia contradicción y limitación. 
TORRES, R. D

Ahora bien, ¿en qué punto el crecimiento económico resolverá incidirá positivamente en la situación de los desposeídos? Cuando sea lo suficientemente voluminoso para que empiece a derramarse a toda la sociedad elevando sus ingresos y por esa vía, satisfacer las necesidades básicas de los excluidos. El punto de conflicto es que no existe una medida, un indicador de magnitud que permita tener esperanzas para que los "condenados de la tierra" encuentren por fin respuesta a sus necesidades. En consecuencia, será necesario seguir esperando. Se infiere que la tan repetida consigna sobre la llegada de inversión extranjera a los países para resolver sus déficit es parte de las verdades que mienten, pues la inversión para que actúe en un país impone condiciones rigurosas: entre las que se pueden mencionar un marco legal que le dé seguridad jurídica; tasas impositivas preferentes; desarrollo de infraestructuras; diseño de políticas tal como retiro del Estado de la actividad económica; privatización de toda actividad que sea susceptible de negocio; restricción de la agenda social; liberación de precios, control del gasto público mediante la congelación de los salarios en el sector público y libertad a los privados para negociar directamente con los trabajadores; subordinación de la actividad política al crecimiento económico; reprogramación de deudas; integración al comercio exterior, especialmente a través de la firma de tratados de Libre Comercio; tasas de cambio flotante para eliminar la diferencia entre la cotización oficial y la del mercado; reducción de aranceles, eliminación de gravámenes a la importación de materias primas, creación de Zonas Francas libres de aranceles, entre otras decisiones. En fin, el Estado debe limitarse a las funciones de seguridad y orden público. En este contexto de amplias facilidades a la inversión surge un tipo de capital agresivo y despiadado: el "capital golondrina" con el único propósito de optimizar el beneficio aprovechando las ventajas de los mercados financieros desregulados, independientemente de los efectos perniciosos que produzcan en las economías.

Como corolario de las exigencias que el inversionista impone surge otro mito de gran impacto. Tal es la separación entre la esfera pública y la privada. Bajo el neoliberalismo asistimos a la ruptura de los límites entre lo público y lo privado porque EI Estado, que representa la esfera pública, es el principal facilitador para el desarrollo privado. La calificación de dispendioso, mano rota, mal administrador, ineficiente, clientelar, y como contra parte, el accionar privado lleno de virtudes impulsa al Estado a entregar a los privados funciones que tradicionalmente había asumido. Lo grave es que funciones tan sensibles y fundamentales para la ciudadanía como son salud y educación se convierten en iniciativas privadas con fines de lucro. Hasta el presente, todas las evidencias muestran que la privatización significa concentración del poder económico y no puede ser de otra manera pues quiénes poseen poder económico están en condiciones de hacer prevalecer sus intereses sobre los demás. Es el Mercado, el nuevo ídolo frente al cual es necesario postrarse, la nueva religión, el nuevo dogma. Los problemas de la humanidad, especialmente los que afectan a los más desposeídos serán resueltos con la intervención del mercado. ¿Cómo?, no se sabe, pero hay que confiar en sus efectos mágicos y si en el pasado se le llamó "la mano invisible", en la actualidad el neoliberalismo lo considera la panacea. Si todo se puede comercializar, si de todo se puede obtener beneficios, la única ética plausible es la del merca 
do, es decir, el mercado de la ética. Rota la frontera entre lo público y lo privado, la alternativa es "sálvese quien pueda".

Visto de este modo el crecimiento económico se transforma en un gran mito.

\section{MITO DEL PROGRESO Y EL DESARROLLO}

Si es cierto que las ideas mueven al mundo, el modelo capitalista en su versión más reciente, el neoliberalismo, requiere de un acompañamiento cultural, de un repertorio de valores, de ideas que le den soporte. En particular, un par de exitosos símbolos ha servido de comparsa a los intereses del modelo. Se trata de las ideas de progreso y desarrollo. A su amparo, bajo su alero encantador se justifican desde las embestidas a la naturaleza hasta las agresiones a las culturas originarias sobre todo si aquellas se convierten en obstáculo para el desarrollo de las transnacionale ${ }^{14}$ El conjunto de medidas económicas, técnicas y políticas del neoliberalismo implican una transformación socio cultural, un horizonte de sentido diferente que debe ser acompañado por un repertorio simbólico seductor que funcione como un imán para atraer la atención de la población, o de la clientela, y justificar cualquier medida por agresiva que sea. Sin embargo, el hechizo de esos dos códigos, de pronto, ha perdido su efecto, pues, lo que prometía ser el tiempo de las grandes conquistas humanas gracias a un desarrollo científico-técnico formidable y a un crecimiento económico que parecía imparable, un sueño glamoroso pleno de ornamentos y colores, el progreso y el desarrollo, inesperadamente se transformaron en una pesadilla cuando la humanidad despierta acosada por la otra cara del progreso, la que no aparece a primera vista, pero que está allí y cuando se rebasa cierto margen de tolerancia se manifiesta con toda su carga de presión. También es manifestación del progreso la polución; la contaminación; la lluvia ácida; el efecto invernadero; la desertificación; la destrucción de la capa de ozono; la inversión térmica; la extinción de especies; la acumulación de residuos y desechos sólidos y líquidos; el calentamiento global; el cambio climático; la eliminación de minerales y desechos radioactivos; la contaminación de suelos por efecto de aguas percoladas; la destrucción de hábitat naturales; la deforestación; la contaminación de mares y ríos; las así llamadas "zonas de sacrificio", es decir poblados que están permanentemente expuestos a contaminación por su cercanía a industrias, deslaves o cercanas a vertederos; las poblaciones que viven en zonas de riesgo por su sismicidad o que ocupan lechos de río; la apropiación del agua por parte de empresas privadas para la producción agrícola dejando a conglomerados humanos sin este vital líquido, todos fenómenos frecuentes que son la otra cara del progreso, que lo acompañan y que hasta ahora son inevitables. Los mecanismos naturales de reciclaje y regeneración son insuficientes para procesar ingentes cantidades de elementos nocivos.

Por otra parte, las tradiciones de los pueblos ancestrales, sus símbolos y ritos, son valorados como resabios de un pasado remoto que debe eliminarse porque obstaculizan la modernización de los aparatos industriales, especialmente si se trata de empresas transnacionales. No importa que se atropellen campos santos, que se pisoteen símbolos sagra 
TORRES, R. D

dos, que se ridiculicen costumbres ancestrales, que se desprecien conocimientos adquiridos o que se destruyan glaciares, se arrasen bosques, se desvíen cauces de ríos, se rompa la cadena alimenticia eliminando especies inconvenientes para la producción. Si alguna conciencia inquieta protesta, la respuesta es que se trata del costo inevitable del progreso y el desarrollo que producen bienestar, es decir, consumo de bienes y servicios que supuestamente, están al alcance del consumidor aun cuando se sabe que un sector de la población está bajo el límite de sobrevivencia y otro sector, con dificultad cubre las necesidades básicas. Puestas así las cosas, la otra cara de la moneda es la opulencia, el consumo que trasciende las necesidades humanas pues se trata de sobre consumo. Rigurosamente hablando el bienestar y el progreso que se ofrecen están al alcance de minorías privilegiadas, pues la distribución de la renta es notoriamente desigual ya que la concentración de la riqueza está en pocas manos. Para disimular la asimetría en el reparto de los bienes los organismos internacionales han creado indicadores que dicen poco y que ocultan mucho. Tal es la Renta Per Cápita, un cálculo matemático que resulta de la división del PIB por el número de habitantes de un país. Lo que se oculta tras esa cifra es que el reparto es desigual a lo que se agrega que el pago de impuestos no es proporcional a la magnitud de la riqueza de las personas ${ }^{15}$. Los gobiernos, en general, cuando no pueden obtener recursos del mercado externo, los extraen del mercado interno mediante la aplicación de impuestos muy regresivos tal como el IVA o impuesto al valor agregado que afecta en la misma magnitud a las rentas altas, medias y bajas. Los problemas del desarrollo capitalista que intenta resolver el Neoliberalismo son los que crea el mismo. $Y$ todo el nombre del progreso, del desarrollo. $Y$ es así porque el progreso y el desarrollo cumplen la función de una ideología que permiten integrar y dar apariencia de unidad a una realidad social escindida.

El progreso es un mito que es realmente efectivo para los que tienen poder adquisitivo.

\section{MITO DE LA SOBERANÍA POPULAR}

Por largo tiempo, (desde la llustración) nos convencieron que la soberanía reside en el pueblo que es quien detenta el poder y que mediante el rito del voto designa a las autoridades que encabezan los destinos de la nación. Nos enseñaron que bajo el principio de la autoridad delegada y la responsabilidad compartida el soberano, el pueblo, por mayoría, decide a quién entregar el ejercicio del poder y a la vez se convierte en co responsable del destino nacional. Un discurso de honda penetración en la población por el atractivo que ejerce porque brinda la ilusión de gobernantes que no son autócratas, sino que están sujetos a la decisión popular. En palabras de estos días, una narrativa seductora y a la vez penetrante porque el soberano es la masa de ciudadanos, o mejor dicho, la ciudadanía se corporiza, se materializa en el endoso de su cuota de poder que cada uno de los integrantes del colectivo entrega al gobernante. De esta manera, todos, partidarios y opositores, forman parte de la gobernanza, unos por adhesión, otros por oposición, pero nadie está excluido. Para los que están en el poder la tarea es apoyar al gobernante para que las decisiones interpreten el sentir popular, para los opositores el desafío es convencer que son alternativa al poder porque dispo 
nen de una oferta mejor, más eficiente y más realista. Con todo lo discutible que pudo haber sido la promesa de la soberanía popular, sin embargo, permitía el funcionamiento de democracias que formalmente expresaban que el poder lo tenía el pueblo, incluso posibilitaba que los gobernantes estuvieran sometidos al escrutinio público, y en más de una ocasión fueron sentados en el banquillo de los acusados. La alternabilidad de distintos bandos en disputa por el poder permitía una cierta paz social pues albergaba para los opositores la esperanza de que el desgaste que implica el ejercicio del poder, fuera el caldo de cultivo para el descontento popular para que en el siguiente ejercicio del rito del voto permitiera ser una opción de gobierno diferente. Así, a pesar de que los cambios de mando finalmente no conformaban al electorado, pues, finalmente la diferencias entre unos y otros solo eran de matices o de colores y los grandes problemas que acosaban a las poblaciones se mantenían sin grandes variaciones, la soberanía popular era un hecho y funcionaba como un lenitivo, como un paliativo esperanzador para la población. Lenta pero constantemente la soberanía popular comienza a desvanecerse cuando se comprueba que las decisiones fundamentales para una nación se toman lejos del soberano, en centros donde habita el verdadero poder. En conformidad con este escenario, sobre la realidad latinoamericana, aunque para el común de las personas tenía más bien existencia tácita antes que efectiva, empiezan a cobrar fuerzas y presencia constante siglas de organismos que copan el imaginario popular: el FMl, el BM, el BID e incluso la TROIKA. Entraba en escena una nueva realidad, efectiva, contundente: la globalización que a pesar de la imprecisión del término "es la intensificación del accionar político de una constelación de instituciones supra nacionales con capacidad estatal (e instituyente) a nivel mundial"16 o, si se quiere un "incremento en el tráfico económico y cultural, que coincide con la hegemonía del capital financiero y de las corporaciones transnacionales, apoyada en el extraordinario desarrollo de la tecnología de las comunicaciones ${ }^{117}$ Mucho más explícito y descriptivo es Robert Reich quien, sin rodeos, afirma “Estamos pasando por una transformación que modificará el sentido de la política y la economía en el siglo venidero. No existirán productos ni tecnologías nacionales, ni siquiera industrias nacionales... Lo único que persistirá dentro de las fronteras nacionales será la población que compone un país..."18 Formidable declaración que muestra el auténtico sentido de la globalización neoliberal, en cuanto a construir una civilización controlada por aparentemente extrañas fuerzas inasibles, etéreas, supra nacionales, ubicuas, pero que tienen domicilio, identidad, residencia: es el poder del capital financiero internacional que ya no se siente cómodo en los límites estrechos de una nación y su zona de influencia, sino que necesita expandirse e imponerse irrestrictamente, sin trabas, sin obstáculos. Si en el pasado un cabo llegó al poder y proclamó la necesidad de "espacio vital" para su país, creando una verdadera carnicería humana, hoy el capitalismo neoliberal para continuar con su reinado quiere abolir las fronteras, integrar las naciones, unificarlas por el mercado quizás con un costo humano horroroso porque se trata de la exclusión, de la marginación, de la expulsión de multitudes de los bienes y servicios, pero mucho menos impactante que la muerte violenta provocada por la guerra. 
TORRES, R. D

La globalización neoliberal ha convertido a la soberanía popular en un mito.

\section{MITO DE LA LIBERTAD}

En occidente la doctrina económica y social imperante ha sido el Liberalismo. Ahora, si se considera el escenario internacional creado al término de la segunda guerra mundial, no hay lugar a la menor duda de que así ha sido. ¿Cuál es la esencia, la idea fuerza que contiene el liberalismo desde los padres fundadores? La libertad, ese código polisémico que se interpreta según necesidad, según circunstancia o interés, ha sido y es el gran símbolo, uno de los pocos que tiene la energía para mover multitudes, para arrastrar a conglomerados humanos hasta el precipicio por alcanzarla, que ha regido los destinos de las naciones, es la sustancia del liberalismo. Es la convicción de que todo progreso deriva de la libre iniciativa de los individuos. Son las creaciones singulares de las personas las que han desarrollado inventos, aparatos, procedimientos, técnicas. Se trata de la libertad individual, la libertad de conciencia, la capacidad que tiene cada persona por elegir la opción de vida que mejor le parezca, le convenga o lo interprete.

Los fundadores del Liberalismo hacen una ardorosa defensa de la libertad individual, ese ámbito en el cual el comportamiento de las personas tiene escasos límites, salvo los que afectan a otras personas. La defensa de la libertad individual necesariamente tendría que manifestarse y traducirse en conducta objetivas en el comportamiento social, pues, si proclamo mi libertad, necesariamente hay que considerar la libertad de otras personas. Puestas así las cosas debemos suponer que los Liberales en su comportamiento social trasladan los valores de la libertad individual. Sólo a título de ejemplo se menciona el caso de uno de los fundadores del liberalismo, Jhon Locke, y el de un país que también lo abrazó. Locke a pesar de su potente discurso libertario era accionista de la Royal African Company, una compañía que comercializaba esclavos negros traídos de África ${ }^{19}$. Holanda surge a consecuencias de la revuelta contra Felipe II y de inmediato inició su expansión de ultramar en el comercio y la trata de esclavos africanos ${ }^{20}$. Si ir tan lejos la conquista de América por parte de los españoles se hizo con la misma ideología de sometimiento y exterminio de los nativos. Basta recordar la conocida polémica que el Padre Las Casas resolvió a favor de los indios diciendo que tenían alma ${ }^{21}$. Fue el trabajo de los esclavos, independientemente de su género, el que le permitió a Europa fortalecer su desarrollo económico y a España incorporarse al naciente capitalismo con relativo éxito. Queda en claro que los promotores de la libertad tenían un concepto bastante sesgado de ella, pues, era válido irrestrictamente tratándose de sus pares, de los blancos, pero con respecto a los pueblos que los europeos sometieron, las consideraciones sobre la libertad no se tenían presente. Si el liberalismo se inscribe en una tradición de defensa de la libertad, ¿cómo se entiende que en sus orígenes los trabajadores fueran considerados objetos y que hubiesen defendido la esclavitud en el mundo colonial? Una contradicción flagrante.

Si se admite que la libertad es intransable y hay que defenderla hasta sus últimas consecuencias, entonces, surgen inquietudes difíciles de resolver. Por ejemplo, la libertad permite a cada persona disponer de sus vidas, y por lo tanto la eutanasia y/o el suicidio, serían 
la máxima manifestación de la libertad individual ${ }^{22}$, ¿por qué el aborto no?, ¿por qué se impide con severas normativas? Quiere decir que la tan proclamada libertad del Liberalismo tiene varios potentes límites que la mediatizan a intereses oscuros y le imponen restricciones. Lo que no se puede ignorar es la imposibilidad de libertad individual porque los hombres desarrollan sus vidas en conjunto con otros hombres, en sociedad y cada sociedad crea un repertorio de comportamientos, de modos de ser y actuar, establece pautas que permiten, que prohíben, que incluye creencias, expresiones artísticas, moral y que en su conjunto conforman la cultura. Se infiere que la libertad existe dentro de los límites que establece cada cultura, cada sociedad. No hay libertad sin límites.

La libertad a ultranza que proclama el Liberalismo dentro de su narrativa, se circunscribe preferentemente a la economía. Es la libertad para desarrollar empresas, para obtener ganancias, para que los mercados, el gran ícono, actúen libremente sin intervención del estado, sin regulaciones que entorpezcan su desarrollo. Los mercados están llamados a incrementar la producción, a mejorarla, a diversificarla, a señalar qué producir, a qué costos, a fijar el monto de los salarios ya que de esa forma se manifiesta la libertad de los individuos y sus iniciativas. Pero ocurre que la libertad es una variable dependiente de la necesidad. Dicho de manera directa, es libre quien tiene medios materiales de vida satisfactorios pues esa base material le permite optar entre un abanico de ofertas disponibles. A la inversa, quien carece de recursos suficientes de vida, simultáneamente tiene muy pocas posibilidades de elegir, de ser libre, pues, en lenguaje ortegiano es una persona alterada en función de la lucha por sobreviviri ${ }^{23}$.

Hay un aspecto de la sociedad neoliberal que proclama la libertad que no aparece en el primer plano y que tiene incidencia directa en la libertad de las personas. El extraordinario desarrollo alcanzado por las Tecnologías de Comunicación y la Información, aliadas directas del modelo, hace que la vida de los hombres esté permanentemente vigilada ${ }^{24}$. Cada vez que se pasa por un peaje, por una alcabala, que se realiza una operación bancaria, que enviamos un mensaje, que se utiliza WhatsApp, que se maneja una red social, que se visita YouTube quedan las huellas y es posible reconstituir con gran precisión los pasos dados en un día, las preferencias de las personas, sus gustos, sus deleites. Las TIC'S cumplen la función del panóptico que describe Foucault ${ }^{25}$, pues, estamos vigilados en todos nuestros movimientos sin posibilidad de eludir el ojo que nos vigila.

En esta línea hay dos aspectos que llaman la atención en relación con la impronta de las TIC'S. Uno es que a pesar que se sabe que hoy, más que en otros tiempos, la sociedad está hipervigilada, que la tecnología permite incluso escuchar las conversaciones independientemente del espacio donde se desarrollan, y que además están cambiando la vida de las personas, están alterando valores, subvirtiendo tradiciones, desintegrando tejidos sociales que se consideran sólidos ¿por qué no existe una reacción potente contra las TIC'S?, ¿será por el encanto que ofrecen al darnos la sensación de estar participando en hechos ocurridos en latitudes lejanas en tiempo real?, ¿será porque facilitan la vida de las personas? La otra cara de esta moneda Las preguntas se multiplican y a la vez son una invitación a refle 
TORRES, R. D

xionar sobre un tema apremiante. La otra cara de esta moneda, es que el control de las TIC'S está en manos de poderosos consorcios capaces de formar matrices de opinión, de hacernos creer que la mentira es verdad, que la apariencia es la realidad. Y así como por medios de las TIC'S ha sido posible denunciar a dirigentes, incluso gobernantes, registrar las múltiples expresiones de la represión con las aspiraciones populares, también por medio de su uso se desatan enormes campañas de demonización de dirigentes sociales, de satanización de justas luchas.

La libertad del Neoliberalismo es un mito.

\section{LA EDUCACIÓN A LA LUZ DE LA MITOLOGÍA NEOLIBERAL}

A la luz de los antecedentes someramente expuestos, la educación como una función social importante no escapa a las determinaciones que provienen del neoliberalismo y por eso en Latinoamérica ha adquirido una singularidad que es necesario develar.

Quizás, para no incurrir en ingenuidades lo primero que se debe precisar es que la "neutralidad" en la educación no existe y esto por la simple razón que es el medio fundamental, junto a la familia, que la sociedad, por medio del Estado, cuenta para difundir, internalizar, promover un cuerpo de valores que permite que los ciudadanos participen de una atmósfera común. Es el recurso que toda sociedad dispone para que el significado del no otros se encarne en sus ciudadanos. La educación desarrolla una cosmovisión que incluye los códigos básicos para participar en un tipo de sociedad. Dicho de otra manera, sería imposible que la sociedad se desarrollara sin que sus integrantes se sintieran participando de un destino común en sentido nacional, cultural, político, lingüístico, tradicional y con esta impronta la neutralidad es una falacia. Adicionalmente, las confesiones religiosas que desarrollan labor de adoctrinamiento en sus templos, también crean escuelas con definida orientación doctrinal y en la enseñanza pública, a pesar de su laicismo, una visión de la religión está presente. La educación formal es la expresión del poder que modela, estructura el saber, organiza y dispone la racionalidad que orienta los estudios, que fija los fines y dispone la forma de difundirlos.

Por otra parte, y enfatizando la idea antes expuesta hay que precisar que la educación ha estado y está en el centro de la discusión política y admitiendo la validez de esta afirmación, fluye que la Política (con P mayúscula) se manifiesta muy palmariamente en la educación. Quien no lo admita es un ingenuo o es un negacionista. Baste con recordar las grandes polémicas que en el pasado se escenificaron en distintos países cuando se abordaba el tema de la educación para las clases trabajadoras, pues, la educación tiene un potencial de subversión, contiene una dosis importante rebeldía porque permite asomarse a los laberintos por donde el poder opresor de las minorías se cuela sometiendo a las mayorías. Por ejemplo “Delvalle (1990, pág. 22-23) se hace eco de una carta anónima publicada en 1797 por el Gentleman Magazine, que decía: Las ocupaciones laboriosas [...] deben ser realizadas por aquellos que nacieron en los niveles más bajos; pero nadie se sentirá dispuesto a ocuparse de los empleos más serviles o de las faenas más desagradables, si su mente se abre y sus capacidades aumentan mediante cualquier posible mejora escolar que se les proporcione" ${ }^{\prime 26}$. 
Con otra perspectiva en la vereda del frente estaban los que defendían una escuela sin trabas para el acceso de los jornaleros, peones o braseros. La polémica finalmente se resolvió creando una escuela universal, pero con circuitos definidos tal como hasta nuestros días. Se configuró una organización educativa que reflejaba casi bis a bis la estructura social. La escuela primaria para los trabajadores, la educación media para las clases medias y la superior para los sectores acomodados o pudientes. Cada uno de estos tramos educativos tenía funciones definidas. La escuela primaria impartía las técnicas básicas de comunicación, lectura, escritura y cálculo matemático que además eran imprescindibles en el mundo del trabajo, junto con determinado conjunto de valores especialmente de orden disciplinar, los necesarios para la producción fabril o la racionalidad administrativa. Aun en nuestros días, en las escuelas primarias se exige formación para entrar al salón de clases, y en el pasado reciente, se revisaba el pañuelo, las uñas cortadas, el cabello ordenado. En el caso de Venezuela concretamente hubo un funcionario llamado Policía Escolar que velaba por el comportamiento ciudadano de los estudiantes al entrar y al retirarse del plantel. Se trataba de la función "civilizatoria" que la escuela debía cumplir con los hijos de los trabajadores. Detrás de esta labor educativa estaba el conflicto entre civilización y barbarie identificado claramente por Domingo Faustino Sarmiento ${ }^{27}$. Un tema apasionante, aunque no es este el momento para abordarlo.

Si bien en Chile se inicia la experiencia neoliberal, sin embargo, existen antecedes que venían advirtiendo que la educación estaba en la mira del sector empresarial. En efecto, en Le Monde Diploma tique, hace ya dos décadas y algo más, Gérard de Salís, publicó un trabajo titulado "Una loca ilusión de tecnócratas y de industriales. La Escuela, gran mercado del siglo $X X I^{\prime}$. El autor aporta datos relevantes "Mil millardos dólares, es, según la OCDE, el monto de los aportes anuales de los estados miembros de la Unión Europea en educación. Un mercado de esta magnitud es altamente apetecido. Cuatro (4) millones de profesores, ochenta (80) millones de alumnos y estudiantes, trescientos veinte mil (320.000) establecimientos escolares de los cuales cinco mil (5000) son universidades y escuelas superiores, están en la mira de los inversionistas ${ }^{\prime 28}$. Se desprende de la cita, que si para 1998 las cifras eran apetecibles para los inversionistas, pues el riesgo de pérdida es mínimo y el beneficio alto, es de imaginarse cómo será la situación en la actualidad. La gran preocupación del sector empresarial es que es el fisco el que maneja esos fondos en circunstancias que esa masa monetaria podría ser controlada por la empresa privada. Sin ir tan lejos, y como muestra de la uniformidad de criterios del capital neoliberal, en Latinoamérica y con ocasión de la V Cumbre de presidentes celebrada en Barranquilla y que contó con la presencia del entonces presidente de los Estados Unidos, Barack Obama, una cantante popular, Shakira Isabel Mubarak Ripoll, más conocida por su nombre de pila, Shakira, tuvo una participación especial ante los representantes de transnacionales y empresarios que acompañan a los presidentes en sus giras. Por varios minutos la cantante ocupó la atención de los presentes para hablar de educación. Dijo "Está demostrado que por cada dólar invertido en la educación temprana de los niños, ese mismo niño devuelve al estado U\$ 17 en su edad adulta: 1 U\$ invertido, U\$ 17 
TORRES, R. D

de retorno. Ustedes que son los expertos en negocio, señores, yo creo que se dan cuenta que está clarísimo que es un buen negocio para todos ${ }^{129}$. Efectivamente, esa es la mirada del neoliberalismo: la educación es un negocio, es un asunto de mercado y debe estar al servicio de aquél. Con este enfoque lo que ha producido el neoliberalismo ha sido un golpe severo a la estructura de la educación pública. Por ejemplo, mediante un torcido manejo de la política de descentralización lo que produjo fue una desconcentración. Así, sin mayor diagnóstico, numerosas escuelas fueron pasadas a las municipalidades sin tener presente que los ingresos de estas corporaciones son muy disímiles y depende fundamentalmente de la población a la que pertenece. Hay municipios que cuentan con presupuesto abundante hasta como para hacer ornatos en las calles, y otros que solo cubren el gasto corriente, es decir, los salarios de los trabajadores. Por eso es que no hubo descentralización pues no se transfirió presupuesto ni una cuota de poder, solo desconcentración.

En estricto rigor la relación de las empresas con la educación es de larga data, pues desde mucho, las editoriales por ejemplo buscan que determinadas escuelas exijan los textos por aquellas producidos; la empresa de cereales Kellogg, financia becas incluso hasta para post grados, otro tanto ocurre con Coca Cola, Michelin y así por el estilo. La diferencia está en que ahora con la vigencia del neoliberalismo la educación es parte integrante del modelo como una actividad mercantil más.

Para el neoliberalismo la educación es una tarea similar a la de una fábrica. Hacer de cada persona competente para crear empleo, cambiar empleo, buscar empleo como rezaba la Ley de Educación argentina. Por eso la búsqueda a ultranza de la eficiencia es una meta que se ha traducido en la optimización de la relación costo-beneficio. Así se explica que en educación se haya incorporado una extraña jerga proveniente del mundo empresarial. Tal es el exitoso código calidad de la educación, respecto del cual toda autoridad gubernamental, todo político, todo profesional de la educación lo sostiene como uno de los fines a lograr en la educación. Lo que se oculta es que esta idea surgió en el Japón de post guerra como una necesidad de la industria de ese país por incorporarse a circuitos internacionales de comercialización $^{30}$. Desde esta coordenada "empresarial" nació la idea de reunir en el nivel de decisión de las empresas a técnicos, mandos medios y trabajadores para que en conjunto decidieran qué producir, en qué volumen, con qué procedimientos, en qué tiempo. La conjunción de la experiencia de los trabajadores y la formación teórica de los técnicos fue una feliz ocurrencia. El epítome del éxito de los círculos de calidad lo representa la empresa fabricantes de autos Toyota y por este motivo suele identificarse erróneamente a esta empresa como la creadora de la iniciativa que desde su nacimiento destelló frente a su rival norteamericana, la Ford ${ }^{31}$. Desde la empresa la categoría calidad pasa a la educación y en este punto surge la confusión pues un producto fabril, un artefacto, es posible apreciarlo por el valor de sus materiales, por su ergonomía, por su diseño, por su marca, por el confort que ofrece, en fin, una compilación de indicadores objetivos y mensurables que permiten realizar una estimación bastante aproximada de su calidad. En el complejo universo de la educación, incluso reduciéndola a escolaridad, ¿quién puede determinar su calidad? ${ }^{32}$ Algunos, desde el punto de vista social, sostienen que una educación es de calidad si atiende a la población de un país que demanda el servicio; otros, desde la psicología afirman que una educación es de 
calidad si logra un desarrollo armonioso de la personalidad de los estudiantes; hay quienes ponen el acento en los contenidos, otros en la gestión de la escuela, todavía hay quienes consideran que una elevada cantidad de promovidos y un mínimo de aplazados es un hito de la calidad, o, la cultura colaborativa, o los valores que difunde e internaliza, o la taza de retención del sistema se han considerado indicadores de calidad. En esta línea de discernimiento sobre la calidad Días Sobrinho (2010) propone la pertinencia y la inclusión como criterios centrales de Evaluación de la Calidad aunque deja en claro que "La calidad, tanto en su conceptualización como en sus prácticas ... es siempre una construcción social que surge de procesos participativos y contextualizados ${ }^{\prime \prime 3}$. La calidad, en educación, es una categoría polisémica, es el tipo de códigos que se han vuelto de plástico, pues tiene múltiples usos. A tal extremo se ha llegado que, en una ciudad de Venezuela, Puerto Ordaz, una escuela privada colocó una inmensa valla o pasacalle anunciando que la calidad de la enseñanza estaba garantizada en la escuela porque el establecimiento se regía por las Normas ISO, es decir por stándares que se utilizan en las industria y que abarcan muchos aspecto que van de la higiene y seguridad hasta el tipo de materiales utilizados.

En la concepción neoliberal la calidad ha dado paso a un elaborado sistema de medición que se institucionalizó en las Agencias de Acreditación, que indican cuáles son las escuelas de calidad. En el laboratorio social chileno existe el SIMCE' ${ }^{34}$, Sistema de Medición de la Calidad de la Educación, que posibilita establecer diagnósticos sobre escuelas con altos y bajos rendimientos. Está demás decir que los puntajes más altos corresponden a escuelas privadas que atienden a estudiantes provenientes de sectores sociales de ingresos mediosaltos y altos. Obviamente las escuelas municipalizadas de los sectores populares aparecen en los niveles bajos.

No se puede evitar decir que las mediciones escolares han servido para fines distintos a los que proclaman. En efecto, un riguroso estudio de Leon Kamin, con suficientes elementos muestra que la idea extendida sobre el carácter hereditario del Cociente Intelectual, no resiste mayor análisis. Si durante largo tiempo distinguidos académicos británicos la sostuvieron fue por razones de orden político y racial. El autor afirma que en Norteamérica los test de inteligencia han sido promovidos por personas que estaban comprometidas con una determinada visión de la sociedad. "La consecuencia de ello es que los test de C.I han servido como instrumento de opresión contra los pobres, revistiéndose con el manto de la ciencia y no con el de la política"35.

En este contexto, el análisis de las mediciones internacionales que tanto deslumbran en nuestros medios, tal como la prueba PISA (Programme for International Student Assessment) o, Programa para la evaluación internacional de estudiantes es una asignatura pendiente que impone un breve comentario.

Lo primero que salta a la vista el elevado costo en divisas que impone la participación en la prueba que para algunos países representa un ingente esfuerzo económico, 0 al menos desviar fondos para renglones que son prioritarios. Luego, todas esas pruebas son descontextualizadas, pues operan sobre la base de un promedio, una entelequia que solo 
TORRES, R. D

existe formalmente hablando. Homogenizando a los participantes los somete al mismo rasero o cartabón en circunstancias que se trata de diferentes sistemas educativos de diversos países que tienen condiciones económicas y sociales distintas y bien sabemos que no hay peor forma de injusticia que hacer la igualdad entre desiguales. Desde el punto de vista educativo se omite el currículo prevaleciente en cada país; tampoco hay participación de los maestros en el diseño y elaboración de la prueba los cuales son reducidos a cumplir el ingrato papel de guardianes o vigilantes cuando se la aplica. Desde el punto de vista metodológico, diversos investigadores, especialmente británicos, han sometido a la prueba a una verdadera disección mostrando sus incongruencias y contradicciones, de manera que confiar en efectos benéficos que las referidas experiencias puedan producir sobre los sistemas educativos, luce como una apuesta riesgosa. Por último, en este superficial examen, hay que decir que existe un evidente conflicto de intereses, pues la OCDE creadora y administradora de la prueba es la que luego maneja los datos, los interpreta, hace las recomendaciones y/o sugerencias conforme al modelo de economía y sociedad que aspira esa organización, es decir, se paga y se da el vuelto.

Lo que si queda en claro es que en la concepción neoliberal la educación es sometida a indicadores ajenos, extraños a la tarea de educar porque para hacerlo se necesita financiamiento y este ha sido un flanco por donde factores distintos y distantes de la educación han ingresado a ella. La inevitable relación entre educación y financiamiento se transformó en una alianza estrecha y determinante con entidades internacionales de como el Banco Mundial, el Banco Interamericano de Desarrollo y el Fondo Monetario Internacional que a través de los Ministerios de Economía pasaron a intervenir directamente en educación fijándole sus políticas. No resulta extraño entonces que docentes, estudiantes, administrativos y trabajadores en general se convirtieron en un recurso, es decir, un medio, un instrumento que hay que optimizar para que se logre la eficiencia, tanto interna como externa. El efecto inmediato desde el punto de vista ético es la cosificación de las personas, la pérdida de su dignidad intrínseca. A tal extremo de mercantilización de la educación se llega que en algunos países se desarrollan "Ferias Anuales de oferta educativa", privada obviamente, especialmente en educación superior. Con esta racionalidad la educación ha perdido su centro y su dinámica dibuja una figura excéntrica, pues ya no es esencialmente un asunto humano, sino un tema de mercado. Es la ley de la oferta y la demanda, la relación costobeneficio la que determina el sentido de la escuela. Desde esta visión transitada mágicamente desaparecen los ciudadanos y la ciudadanía para dar paso a los consumidores, los clientes, los compradores que se realizan en el mercado consumiendo con la utilización del instrumento favorito: el crédito expresado a través de una tarjeta ad hoc, o dinero plástico como normalmente se las conoce. Si en el pasado, cuando la educación se consideraba un legítimo medio para la promoción social, para la integración ciudadana y los partidos políticos desarrollaban tesis o doctrinas sobre la educación y los Estados hacían esfuerzos por extender el servicio educativo, y a pesar de todo esto la educación contribuía a sacralizar las diferencias sociales, es de imaginar la actual situación. El discutible maridaje que se ha producido entre mercado, beneficios y educación contribuye a fortalecer la diferenciación social, a profundizar la segregación entre géneros, a justificar la defraudación de los salarios a los trabajadores que 
recibieron escasa e insuficiente escolaridad, en suma, a acentuar las asimetrías sociales. La educación en parámetros neoliberales ha perdido su encanto y/o romanticismo cuando se la concebía como un camino que ofrecía expectativas, cuando se la pensaba en parámetros éticos como un acto de acogimiento, de hospitalidad.

La escuela que fue la primera institución formadora para la vida democrática, a pesar de sus lacras autoritarias, hoy con un pragmatismo ramplón, el neoliberalismo la ha convertido en mercancía con valor de uso transable en el mercado. Lo más sorprendente de este impacto en la educación es que ha sido presentado en la mitología neoliberal, como "modernización", una narrativa cautivante según lo hemos pretendido mostrar en párrafos anteriores. Frente al profesor honesto, formado en un instituto concebido en parámetros pedagógicos se alza el mercader, el publicista que entra a competir en el mercado ofreciendo bondades, beneficios, premios obtenidos que garantizan supuestamente la mejor educación para la infancia en el plantel que representa. Y como la calidad no es gratuita, las escuelas se cotizan al alza a sabiendas que en la condición humana existe desconfianza si un producto tiene un precio muy bajo. Detrás de la escuela publicitada está el inversor, el que se "sacrifica arriesgando su capital" a sabiendas que las familias hacen los mayores esfuerzos para los hijos se eduquen en el mejor plantel que se ofrece en el mercado. Con estos parámetros las poblaciones rurales, las alejadas de los centros urbanos no son motivo de interés para el inversor y le corresponde al Estado acudir con un servicio las más de las veces deficiente, inadecuado y sin correspondencia con el medio al cual se suponen sirven.

En la escuela-fábrica del neoliberalismo la preeminencia la tienen las técnicas, es decir, las didácticas ${ }^{36}$, lo que no impide reconocer las múltiples e importantes investigaciones que se desarrollan en la enseñanza de las asignaturas tal como lenguaje y comunicación, idiomas extranjeros, matemáticas, entre otras. Quizás el pragmatismo que impera en los tiempos actuales estimula en los profesores la búsqueda de respuestas concretas, específicas y funcionales para enseñar, y en los padres el, deseo que sus hijos aprendan prontamente sin mayores consideraciones. A unos y a otros les interesa la efectividad y en esta tesitura las técnicas aparecen como una respuesta. Ligado a esta postura aparece también el sello de la psicología, probablemente porque los nombres de Vitgostky, Piaget, Ausubel aportan respuestas concretas respecto a la enseñanza. El conflicto aparece cuando el crecimiento de la didáctica se hace a costa de la reflexión sobre la educación, es decir disminuyendo la Pedagogía o sacrificando la filosofía, la historia y en general, las ciencias "inútiles", quizás porque son las que invitan a examinar la realidad con ojos críticos develando lo que está detrás de la apariencia. El crecimiento humano, el desarrollo de la persona, está intrínsecamente ligado a su capacidad de comprender por qué las cosas ocurren de una determinada manera. El desarrollo del pensamiento crítico que en el pasado se postulaba como una meta, la escuela, bajo la impronta neoliberal, lo ha reemplazado por las "competencias" en plena consonancia con la reducción de los sujetos a recursos utilizables. Hay que ser competente porque además las naciones deben ir a competir al mercando mundial. No importa que se trate de países pequeños, con escaso desarrollo tecnológico, con 
TORRES, R. D

poblaciones que se encuentran en el límite de precariedades soportables, con desequilibrios territoriales, con reducidas expectativas de vida, con morbilidades propias de la pobreza. Todos estos inconvenientes se suplen con las "ventajas comparativas", tales como posición geopolítica, recursos naturales, disponibilidad de materias primas, fuerza laboral abundante y barata.

Puestas así las cosas, la escuela dejó de ser el espacio de convivencia para convertirse en un campo de batalla pues la competitividad ha sustituido a la solidaridad, la antítesis de una educación humanista que sensibiliza y que prepara para asumir al prójimo no como un rival sino como alguien con quien compartir, con quien dialogar. Es la idea del sálvese quien pueda.

\section{LA DEMOCRACIA EN LA PERSPECTIVA NEOLIBERAL}

Si se aceptan como válidas las consideraciones hasta ahora expuestas, se infiere que el neoliberalismo como teoría y práctica es un severo obstáculo para que una sociedad se rija por valores democráticos. Neoliberalismo y democracia son dos vías paralelas que por más que se extiendan no se encontrarán jamás. El neoliberalismo, en esencia, es incompatible con la democracia. Una auténtica democracia necesita varias condiciones, por ejemplo, requiere ciudadanos informados, con capacidad crítica para enfrentar conscientemente las opciones que se ofrecen; espacios políticos para que la oferta electoral no tenga límites y los ciudadanos puedan optar sin restricciones; un mínimo de igualdad económica, de condiciones materiales de vida que permitan a los electores sentirse mínimamente incluidos; garantías de que la alícuota de poder que los ciudadanos entregan a los que eligen será respetada y no negociada en función de intereses personales; que el voto no sea un rito, sino una garantía de fiel cumplimiento de lo prometido; que se rompa la extraña ecuación numérica que significa que las mayorías, los que viven de un salario, sean gobernadas por la minorías, los que viven de la plusvalía que genera el trabajo de otros; que las elecciones no se transformen en el mito del eterno retorno, es decir, se vota, la situación no varía y no hay más alternativa que esperar la próxima lección para volver a votar; que las autoridades electas, por lo menos una vez, desciendan a escuchar a sus electores; que no se insista en afirmar que la democracia es el sistema político menos malo porque se fomenta el conformismo y la resignación; que los elegidos por el pueblo gobiernen para él y no para el mercado; que se castigue ejemplarmente a los mercaderes del voto; que los derrotados se autocritiquen y no responsabilicen a los electores de su fracaso situación que se expresa en dichos tal como "no entendieron el mensaje"; que los políticos acepten los resultados de las urnas y no se autoproclamen; que los candidatos sean electos por el pueblo y no por los medios de comunicación; que los militares se limiten a sus cuarteles y no participen en política para desconocer la voluntad popular tal como está ocurriendo en estos días en la sufrida Bolivia; que una vez realizados los escrutinios con observadores internacionales se proceda al reconocimiento del ganador; que el ganador en una elección con una abstención de más del cincuenta por ciento de los electores, sea considerado ilegítimo; que los elegidos no puedan reelegirse hasta pasado un periodo; que los medios de comunicación no formen matrices de 
opinión para lo cual los directorios de esos medios, en sus directorios estén representado los diferentes sectores sociales, incluso las minorías; que los partidos políticos rindan anualmente cuenta pública del monto y del origen de sus entradas y gastos de manera que la ciudadanía esté informada. De esta incompleta enumeración de condiciones para el ejercicio democrático el neoliberalismo difícilmente. Desde esta larga enumeración de condiciones para el ejercicio democrático, aun incompleta, el neoliberalismo difícilmente cumple alguna. Lo que se conoce en Latinoamérica es el frecuente uso de la fuerza legítima del Estado para mantener su estructura de dominación. En estricto rigor la democracia liberal tampoco las cumple. Lo que se conoce como democracia muy poco tiene que ver con sus orígenes. La democracia en Latinoamérica tiene mucho de ritual, de puesta en escena, de maqueta. Lo que se ha visto hasta ahora es que, cada vez que un gobernante intenta favorecer a las mayorías de su país, introduciendo modificaciones a la estructura de la economía, proponiendo una nueva política tributaria para que los aporten sean proporcionales a los ingresos, realizando reformas agrarias para redistribuir la tierra y acabar con los excesos de la propiedad latifundista, entre muchas otras medidas, el resultado es previsible. Las Fuerzas Armadas de la región, salvo excepciones, estrenadas y adoctrinadas en la doctrina de la Guerra Fría y del enemigo interno frente a un triunfo popular reaccionan con el poder de fuego que poseen. El resultado está a la vista: Golpe de Estado y la aparición de extrañas y hasta curiosas categorías tal "como democracia protegida", "democracia tutelada", o "democracia hasta donde sea posible." Es la impronta del autoritarismo la carta reservada para mantener el neoliberalismo el recurso que garantiza la mantención del poder.

La auténtica democracia debe ofrecer protección, cuidado a sus ciudadanos, pero cuando los jóvenes especialmente han sido despreciados o reducidos a clientes ¿pueden creer en ella? No es casualidad que una canción popular de los ochenta, "Súbanse al baile de los que sobran" uno de cuyos versos dice nadie nos quiso ayudar/ oía los consejos, los ojos en el profesor/ y no fue tan verdad/ porque esos juegos terminaron para otros con laureles y futuros/ y dejaron a mis amigos pateando piedras, hasta estos días sea uno de los himnos preferidos por manifestantes en Chile o Colombia. Para los jóvenes, en las proclamadas normas de convivencia pacífica, reverbera un eco de la hipocresía del sistema. Cuando la muchedumbre hastiada de injusticias se lanza a las calles a causar destrozos, a destruir propiedades públicas y privadas, a derribar símbolos del poder, a saquear comercios, no hay duda que se trata de un comportamiento censurable. Ahora si de saqueos se habla, en ellos hay que incluir los latrocinios que a cada rato cometen los políticos, los gobernantes y los uniformados que se apropian de fondos públicos en beneficio personal. Y de estos saqueos es posible hacer una extensa lista. La democracia se basa en principios éticos y si los gobernantes no dan el ejemplo, resulta incongruente pedir a la ciudadanía comportamientos civilizados.

\section{ENTRE LO DESEABLE Y POSIBLE, QUE SE POSTULE LO REALIZABLE}


TORRES, R. D

Con plena conciencia que las salidas a la actual crisis que padecen las mayorías en nuestros países serán el resultado de una construcción social, de una elaboración colectiva, aun así es posible poner en la mesa de discusión algunas consideraciones. La primera es que si alguien está pensando que el modelo neoliberalismo puede ser aventado, está delirando. La instalación de bases militares de los Estados Unidos en la región es mucho más importante de lo que se cree y este es un dato no menor, ya que la alianza entre las fuerzas armadas nacionales y su centro de formación, Estados Unidos, es estrecha. De manera que hay una "gran hermano" ${ }^{137}$ que aprendió la lección y que no tolerará ninguna amenaza a sus intereses. Las posibilidades son, en primer lugar, establecer prioridades frente a necesidades vitales para la población de menores ingresos. Luego avanzar en acuerdos nacionales que moderen los apetitos del capital en relación con los servicios públicos, con la salud y la educación o talvez alguna revisión a las legislaciones leoninas que existen en materia de derecho de propiedad. Quizás una agenda mínima, que contemple reformas al sistema de seguridad social de manera que la masa monetaria que aportan los trabajadores para su jubilación pase de las manos privadas (Administradoras de Fondos de Pensiones) en que está al sector público y se establezcan ingresos mínimos acorde con normas internacionales.

Pero si hay una medida urgente y necesaria esa es que los Partidos Políticos del espectro progresista, las organizaciones sociales de base, los sindicatos y en general las organizaciones de los trabajadores, las agrupaciones vecinales, las organizaciones feministas, las organizaciones LGBTI y todas las formas de organización social asuman de manera masiva y profunda la formación política de los ciudadanos. Así se evitará el activismo ciego que no conduce a nada, se formará a las personas para enfrentar la maraña lingüística con que los economistas disfrazan sus medidas, se formarán los dirigentes y líderes y se elevará la discusión para enfrentar al poder

FINAL

El tiempo de vida de una persona es muy reducido en comparación con el tiempo histórico. Setenta, ochenta años, las posibilidades de vida de un hombre, no son nada para la historia y quizás por esta razón la percepción que embarga a los hombres de este tiempo es de cierta impotencia al constatar que las desigualdades y las injusticias sociales, los abusos del poder, el dominio avasallante del poder económico concentrado en pocas manos, la proliferación de patíbulos y mazmorras para quienes se rebelan son signos desalentadores. Pero como la historia es impredecible, contiene lo inesperado el optimismo es necesario. Pequeños pero significativos avances que ponen en tela de juicio el reinado del neoliberalismo se escenifican sobre la América morena. Los progresos en la integración regional a través del MERCOSUR, el surgimiento de UNASUR, la presencia en México y Argentina de alternativas políticas diferentes a las dominantes, ponen sobre la mesa esperanzas de que en Latinoamérica se está gestando un proyecto político, incipiente aún, como alternativa al neoliberalismo. Los fuertes cuestionamientos que el modelo está recibiendo en varios países de la región permiten vislumbrar posibilidades de cambios. Dependerá de la conducción y orientación que estos sacudones sociales asuman su destino 
final, teniendo presente que el poder tiene como norma que todo hombre tiene su precio, y si no hay sólidos principios, si los valores éticos no tienen primacía, el sacrificio habrá sido en vano. A lo sumo se podría conseguir cambios que no toquen el fondo, debido a que "no es fácil destruir un ídolo: requiere tanto tiempo como el que se precisa para promoverlo y adorarlo, pues no basta con aniquilar su símbolo material, lo que es sencillo, sino también sus raíces en el alma" ${ }^{\prime \prime 8}$. Y en este punto especialmente la educación puede hacer contribuciones importantes empleando las legítimas aspiraciones populares como sustancia para develar lo que las ideas dominantes ocultan. Para ello, educar en democracia y en derechos impone que los docentes asuman su tarea testimoniando prácticas democráticas, ejerciendo respeto a los derechos, fortaleciendo el pensamiento crítico permitiendo que todas las opciones se examinen desprejuiciadamente.

Artigo recebido em: 07/12/2019

Aprovado para publicação em: 05/02/2020

\section{NEOLIBERALISMO E DEMOCRACIA, UM CASAMENTO CONDENADO A DIVORCIAR COM UM FILHO BASTARDO CHAMADO EDUCAÇÃO}

RESUMO: Utilizando o mito como critério de análise, são examinadas a teoria e a prática do neoliberalismo em suas relações com o desenvolvimento democrático e a educação. Inconsistências e fantasias do neoliberalismo são reveladas em sua aplicação, com referência especial ao seu impacto na economia. Nesse contexto, a educação é considerada com critérios comerciais, obscurecendo seu perfil humanístico e sua condição de serviço público para torná-lo mais um recurso para a obtenção de benefícios econômicos. Essas relações entre neoliberalismo, democracia e educação nos permitem afirmar suas incompatibilidades para inferir que o neoliberalismo não é um estágio para o desenvolvimento democrático, muito menos para a educação pública.

PALAVRAS-CHAVE: Mito. Neoliberalismo. Democracia. Educação.

\section{NEOLIBERALISM AND DEMOCRACY, A MARRIAGE CONDEMNED TO DIVORCE WITH A BASTARD SON CALLED EDUCATION}

ABSTRACT: Using myth as a criterion for analysis, the theory and practice of neoliberalism in its relations with democratic development and education are examined. Inconsistencies and fantasies of neoliberalism are revealed in its application, with special reference to its impact on the economy. In this context, education is considered with commercial criteria, blurring its humanistic profile and its condition of public service just to make it one more resource for obtaining economic benefits. These relationships between neoliberalism, democracy and education allow us to affirm their incompatibilities to infer that neoliberalism is not a stage for democratic development, let alone for public education. 
TORRES, R. D

KEYWORDS: Myth. Neoliberalism. Democracy. Education.

NOTAS

1) IBSEN, E__ Obras inmortales. Madrid. EDAF. (1972)

2) En el año de 2006, los estudiantes secundarios, muchachos de 15,16 y 17 años se tomaron las calles, gritaron, bailaron, marcharon y concitaron la atención ciudadana a pesar de los esfuerzos de los medios de comunicación, primero por ignorarlos, y luego por descalificarlos. Esta rebelión, surgida repentinamente, debió haber disparado las alarmas respecto al malestar que estaba instalado en la ciudadanía, pero pudo más la preservación del modelo por parte de la izquierda concertada neoliberal. 3) Hoy se debe admitir que el oasis se secó.

4) PIÑERA, S; el pasado 8 de octubre en el programa Mucho Gusto del canal de televisión Mega. Disponible en:

https://www.publimetro.cl/cl/social/2019/10/20/pinera-chile-crisis-estallido-social-santiago-oasislatinoamerica-el-pais-redes-sociales.html.

5) Redacción: BBC Mundo. Protestas en Chile: "Estamos en guerra", la frase de Piñera que se le volvió en contra en medio de las fuertes manifestaciones, 2019 BBC Mundo Disponible en: https://www.bbc.com/mundo/noticias-america-latina-50139270, acceso en 22 oct. 2019.

6) El crecimiento económico se entiende como la producción de bienes y servicios, el ahorro, el consumo de energía, la inversión, la balanza comercial favorable, entre otros indicadores.

7) FIORAVANTI, E. El capital monopolista internacional. ed. 62, Barcelona: Península, s.f.

8) LOMAS, C. El espectáculo del deseo. Crítica de la publicidad y educación crítica. Bogotá: Cooperativa Editorial Magisterio, 2008.

9) En el caso de Chile, el modelo implementó hábilmente las tarjetas de crédito que estaban a disposición de los ciudadanos sin mayores trámites y que incluso le permitían al consumidor fijar el número de las cuotas de pago, y además, con meses muertos. El beneficio para el capital estaba en los intereses, pues a mayor tiempo la recaudación se elevaba. Esta artimaña daba la sensación de bienestar. 10) KOZLIK, A. El capitalismo del desperdicio, El milagro económico norteamericano. México: Siglo XXI Editores. 1968.

11) Naciones Unidas. Una población en crecimiento. Disponible en: https://www.un.org/es/sections/issues-depth/population/index.html. Oct 2011.

12) MEADOWS, D.H.; MEADOWS, D.L.; RANDERS, J; BEHRENS, W. Los límites del crecimiento: informe al Club de Roma sobre el predicamento de la Humanidad. Reseña por Maite Zapiain Aizpuru. 1972. PDF.

13) China se sitúa entre los primeros lugares de las naciones que más contaminan. (BLOCH, E. Ateísmo en el cristianismo. Madrid. Editorial Trotta. 1972), podemos decir, Neoliberalismo en el Comunismo. 14) A título de ejemplo se puede señalar a la Nestlé a la Bayer, dos transnacionales que ha mostrado en varios hechos que si de ganancias se trata, no hay inconvenientes a adoptar cualquier medida por brutal que pueda parecer.

15) JIMÉNEZ, J. P. Editor. Desigualdad, concentración del ingreso y tributación sobre las altas rentas en América Latina. CEPAL. Santiago de Chile. 2015. PDF. 
16) GRASSI, E. Políticas y problemas sociales en la sociedad neoliberal. La otra década infame (1). Buenos Aires: Espacio Editorial. P. 49. 2003.

17) IBIDEM.

18) REICH, R. El trabajo de las naciones. Hacia el capitalismo del siglo XXI. Buenos Aires: Javier Vergara Editor S.A. P. 13. 1993. (El autor fue Ministro del Trabajo de Bill Clinton).

19) LOSURDO, D. Contrahistoria del Liberalismo. Editor Digital: Titivillus ePub base r2.0. 2005. E-Book. 20) IBID.

21) TEILTELBOIM, V. El amanecer del capitalismo y la conquista de América. $S / d$.

22) ARENDT, H. Tiempos presentes. Barcelona. 2002.

23) ORTEGA Y GASSETT, J. Meditación de la técnica. Ensimismamiento y alteración. Obras Completas. Madrid: Alianza editorial - Revista de Occidente. 1983

24) Un valioso estudio al respecto se encuentra en el libro de (WHITAKER, R. El fin de la privacidad. Cómo la vigilancia total se está convirtiendo en realidad. Paidos. Barcelona. 1999.)

25) FOUCAULT, M. Vigilar y castigar. Madrid: Siglo XXI Editores. Vigésimo tercera edición. 1995

26) PARDO PÉREZ, J. C; GARCÍA TOBÍO, A. Los estragos del neoliberalismo y la Educación Pública. Santiago de Compostela. 2003. PDF.

27) SARMIENTO, D. F. Facundo. Disponible en: http://www.hacer.org/pdf/Facundo.pdf. 1999.

28) DE SÉLYS, G. La escuela, gran mercado del siglo XXI: Un sueño enloquecido de tecnócratas e industriales. Le Monde Diplomatique, Paris, Francia. 1998. Edición francesa. Disponible en: https://librepenicmoncjose.blogspot.com/2010/11/la-escuela-gran-mercado-del-siglo-xxi.html. 27 Nov. $\underline{2010 .}$.

29) DONOSO, T. R. Las lecciones pedagógicas de Shakira. Mérida, Venezuela. PDF. Disponible en: https://www.google.com/url?sa=t\&rct=j\&q=\&esrc=s\&source=web\&cd=3\&cad=rja\&uact=8\&ved=2ahU KEwjugli9gKLmAhWhxVkKHWikCJUQFjACegQIBBAB\&url=https\%3A\%2F\%2Fwww.revistas.ufg.br\%2Fin teracao\%2Farticle\%2Fdownload\%2F20733\%2F12428\%2F\&usg=AOvVaw2EqFkpAIKCWxesHWQsBX0E. Acceso en: 26 Abr. 2012.

30) Gestión de calidad. Disponible en: http://www.educaguia.com/apuntesde/calidad/circulos-mejoracalidad.pdf. S.f.

31) Un aspecto de los círculos de calidad ocultado se refiere a la remuneración de los trabajadores, que pueden participar en el nivel decisorio de la empresa en materia de producción, pero no así en el reparto de las ganancias que es privativo de los accionistas.

32) MARTIN BRIS, M (Coordinador) La calidad educativa en un mundo globalizado: intercambio de experiencia y perspectivas. Alcalá de Henares. 2001.

33) DELGADO, D; GRADIN, A (Compiladores). El Neoliberalismo tardío. Teoría y Praxis. Documento de Trabajo $N^{\circ}$ 5. CLACSO. Consejo Latinoamericano de Ciencias Sociales. Buenos Aires: FLACSO Sede Argentina. Pp 127-128. 2017. PDF.

34) Sobre esta prueba de medición existen varios estudios que cuestionan su metodología, la interpretación de los resultados, su validez. Véase EYZAGUIRRE, B; FONTAINE, L. ¿Qué mide realmente el SIMCE? Disponible en:

https://www.cepchile.cl/cep/site/artic/20160303/asocfile/20160303184442/rev75 eyzaguirre.pdf.

Estudios Públicos, 75. invierno 1999.

35) KAMIN, L. Ciencia y política del cociente intelectual. p. 6. España: Siglo XXI Editores. 1983.

36) ZAMBRANO, A. La educación, el vacío y la frivolidad. La pesadumbre del presente. Argentina: Editorial Brujas. 2017. 
TORRES, R. D

37) ORWELL, G. 1984. PDF. Disponible en: http://www.philosophia.cl/biblioteca/orwell/1984.pdf.

38) CIORAN, E. Adiós a la filosofía. Buenos Aires: Alianza editorial. P. 14. 1994.

BiBLIOGRAFÍA

ARENDT, H. Tiempos presentes. Barcelona. 2002.

BLOCH, E. Ateísmo en el cristianismo. Madrid. Editorial Trotta. 1972.

CIORAN, E. Adiós a la filosofía. Buenos Aires: Alianza editorial. P. 14. 1994

IBSEN, E. Obras inmortales. Madrid. EDAF. (1972)

JIMÉNEZ, J. P. Editor. Desigualdad, concentración del ingreso y tributación sobre las altas rentas en América Latina. CEPAL. Santiago de Chile. 2015. PDF.

KAMIN, L. Ciencia y política del cociente intelectual. p. 6. España: Siglo XXI Editores. 1983.

KOZLIK, A. El capitalismo del desperdicio, El milagro económico norteamericano. México: Siglo XXI Editores. 1968

LOMAS, C. El espectáculo del deseo. Crítica de la publicidad y educación crítica. Bogotá: Cooperativa Editorial Magisterio, 2008.

LOSURDO, D. Contrahistoria del Liberalismo. Editor Digital: Titivillus ePub base r2.0. 2005. E-Book.

MARTIN BRIS, M (Coordinador) La calidad educativa en un mundo globalizado: intercambio de experiencia y perspectivas. Alcalá de Henares. 2001.

MEADOWS, D.H.; MEADOWS, D.L.; RANDERS, J; BEHRENS, W. Los límites del crecimiento: informe al Club de Roma sobre el predicamento de la Humanidad. Reseña por Maite Zapiain Aizpuru. 1972. PDF.

Naciones Unidas. Una población en crecimiento.

ORTEGA Y GASSETT, J. Meditación de la técnica. Ensimismamiento y alteración. Obras Completas. Madrid: Alianza editorial - Revista de Occidente. 1983

PARDO PÉREZ, J. C; GARCÍA TOBÍO, A. Los estragos del neoliberalismo y la Educación Pública. Santiago de Compostela. 2003. PDF. 
Neoliberalismo y democracia: un matrimonio condenado...

Dossiê

PAYNE, M (comp). Diccionario de teoría crítica y estudios culturales. Buenos Aires:

Editorial Paidos. 2002.

PIÑERA, S; el pasado 8 de octubre en el programa Mucho Gusto del canal de televisión Mega. Disponible en:

REICH, R. El trabajo de las naciones. Hacia el capitalismo del siglo XXI. Buenos Aires: Javier Vergara Editor S.A. P. 13. 1993. (El autor fue Ministro del Trabajo de Bill Clinton).

TEILTELBOIM, V. El amanecer del capitalismo y la conquista de América. S/d.

WHITAKER, R. El fin de la privacidad. Cómo la vigilancia total se está convirtiendo en realidad. Paidos. Barcelona. 1999.

ZAMBRANO, A. La educación, el vacío y la frivolidad. La pesadumbre del presente. Argentina: Editorial Brujas. 2017

\section{DOCUMENTOS EN LINEA}

DE SÉLYS, G. La escuela, gran mercado del siglo XXI: Un sueño enloquecido de tecnócratas e industriales. Le Monde Diplomatique, Paris, Francia. 1998. Edición francesa. Disponible en: https://librepenicmoncjose.blogspot.com/2010/11/la-escuela-gran-mercadodel-siglo-xxi.html. 27 Nov. 2010.

DELGADO, D; GRADIN, A (Compiladores). El Neoliberalismo tardío. Teoría y Praxis. Documento de Trabajo N ${ }^{\circ}$. CLACSO. Consejo Latinoamericano de Ciencias Sociales. Buenos Aires: FLACSO Sede Argentina. Pp 127-128. 2017. PDF.

Disponible en: https://www.un.org/es/sections/issues-depth/population/index.html. Oct 2011.

DONOSO, T. R. Las lecciones pedagógicas de Shakira. Mérida, Venezuela. PDF. Disponible en:

https://www.google.com/url?sa=t\&rct=j\&q=\&esrc=s\&source=web\&cd=3\&cad=rja\&uact=8\& ved=2ahUKEwjugli9gKLmAhWhxVkKHWikCJUQFjACegQIBBAB\&url=https\%3A\%2F\%2Fwww. revistas.ufg.br\%2Finteracao\%2Farticle\%2Fdownload\%2F20733\%2F12428\%2F\&usg=AOvVa w2EqFkpAIKCWxesHWQsBXOE. Acceso en: 26 Abr. 2012. 
TORRES, R. D

EYZAGUIRRE, B; FONTAINE, L. ¿Qué mide realmente el SIMCE? Disponible en: https://www.cepchile.cl/cep/site/artic/20160303/asocfile/20160303184442/rev75 eyzaguirr e.pdf. Estudios Públicos, 75. invierno 1999.

FIORAVANTI, E. El capital monopolista internacional. ed. 62, Barcelona: Península, s.f.

FOUCAULT, M. Vigilar y castigar. Madrid: Siglo XXI Editores. Vigésimo tercera edición. 1995

Gestión de calidad. Disponible en: http://www.educaguia.com/apuntesde/calidad/circulosmejora-calidad.pdf. S.f.

\section{GRASSI, E. Políticas y problemas sociales en la sociedad neoliberal. La otra década}

infame (1). Buenos Aires: Espacio Editorial. P. 49. 2003.

https://www.publimetro.cl/cl/social/2019/10/20/pinera-chile-crisis-estallido-social-santiagooasis-latinoamerica-el-pais-redes-sociales.html.

ORWELL, G. 1984. PDF. Disponible en:

http://www.philosophia.cl/biblioteca/orwell/1984.pdf.

Redacción: BBC Mundo. Protestas en Chile: "Estamos en guerra", la frase de Piñera que se le volvió en contra en medio de las fuertes manifestaciones, 2019 BBC Mundo Disponible en: https://www.bbc.com/mundo/noticias-america-latina-50139270, acceso en 22 oct. 2019.

SARMIENTO, D. F. Facundo. Disponible en: http://www.hacer.org/pdf/Facundo.pdf. 1999

Roberto Donoso Torres: Lic. En Educación. Dr. En Ciencias de la Educación. Docente Universidad de los Andes Mérida (Venezuela).

Orcid: https://orcid.org/0000-0003-3857-1434

E-mail: redonoso@gmail.com

Este periódico utiliza a licença Creative Commons Attribution 3.0, para periódicos de acesso aberto (Open Archives Iniciative - OAI). 